\title{
The Present State of the Aspect Hypothesis: A Critical Perspective
}

\author{
Patrick D. Thane a * \\ ${ }^{a}$ The College of New Jersey, Department of Special Education, Language, and Literacy, Ewing, NJ, 08631, United \\ States
}

Received 08 April 2018 | Received in revised form 14 May 2018 | Accepted 02 August 2018

\author{
APA Citation: \\ Thane, P. D. (2018). The present state of the Aspect Hypothesis: A critical perspective. Eurasian Journal of Applied \\ Linguistics, 4(2), 261-273. doi: 10.32601/ejal.464173
}

\begin{abstract}
Early research on the Aspect Hypothesis yielded a rigid developmental sequence for the acquisition of grammatical aspect, in which developing L2 learners applied morphemes to mark aspect in accordance with the inherent lexical aspect of verbal prototypes. While studies from a variety of L2 backgrounds have amassed evidence for this hypothesis, some recent research has questioned its generalizability (i.e. Comajoan, 2005; Izquierdo \& Collins, 2008; Liskin-Gasparro, 2000; López-Ortega, McManus, 2013; Salaberry, 2011). The present analysis of literature reviews the key tenets of the Aspect Hypothesis in order to examine how subsequent studies have demonstrated that L1 influence, syntactic similarities between L1 and L2, the role of inherent lexical aspect, and the use of pedagogical materials in classroombased instruction may have implications for its accuracy in predicting learners' use of temporal morphology. Such implications may affect the degree of accuracy with which this model predicts the acquisition of aspectual morphology in L2 learners, principally at early and advanced stages of proficiency. Lastly, this critical analysis identifies potential directions for future research that would strengthen or modify the recent claims that question the predictive accuracy of the Aspect Hypothesis.
\end{abstract}

(C) 2018 EJAL \& the Authors. Published by Eurasian Journal of Applied Linguistics (EJAL). This is an open-access article distributed under the terms and conditions of the Creative Commons Attribution license (CC BY-NC-ND) (http://creativecommons.org/licenses/by-nc-nd/4.0/).

Keywords: Aspect Hypothesis; tense-aspect acquisition; second language acquisition; inherent lexical aspect; grammatical aspect

\section{Introduction}

\subsection{The present study}

The acquisition of L2 aspect has transitioned from "A small but active area of investigation in SLA," (Bardovi-Harlig, 1994, p. 41) to a field of study that "has generated an intense debate on the acquisition of [morphology]," (Salaberry, 2011, p. 151). Without question, developing the ability to use morphology to articulate aspect is one of the most significant challenges for L2 learners (Murakami \& Alexopoulou,

\footnotetext{
* Corresponding author. Tel.: +1-646-842-1864

E-mail address: thanep1@tcnj.edu
} 
2016; Paradis, Rice, Crago, \& Marquis, 2008). At the center of this investigation lies the Aspect Hypothesis, referenced herein as the AH, which proposes how L2 learners develop the ability to express aspect using verbal inflections. A series of early studies provided evidence in support of a universal sequence for the acquisition of aspectual markers. However, recent studies have indicated that this model is not generalizable to all learners. These researchers have demonstrated that the predictive accuracy of the AH varies depending upon different factors (Bardovi-Harlig, 2000; LiskinGasparro, 2000; López-Ortega, 2000; McManus, 2013; Salaberry, 2003, 2011). Among these factors are L1 influence, L1-L2 structural similarity, contact with L2 native speakers, and the use of classroom materials versus contact with native speakers. The present work examines the findings of these areas of research and the predictions of the $\mathrm{AH}$ presented below.

\subsection{Reviewing tense and aspect}

In order to understand the criticisms leveled at the AH, it is first necessary to have a strong concept of tense and aspect and how they relate to second language acquisition, where grammatical means for communicating tense and aspect in one language may differ from that of another. On one hand, verb tense is a deictic function of grammar that situates an action within the past, present, or future. On the other, aspect is the temporal composition of an action (Comrie, 1976); that is, how statically or fluidly this action moves through one of these tenses. The $\mathrm{AH}$ incorporates two types of aspect: lexical aspect and grammatical aspect. Lexical aspect refers to how the referent of a verb or predicate moves through time. For example, the Spanish verb correr (to run) has a unique aspectual composition in comparison to the verb llegar (to arrive). In the case of the former, the action undergoes an inherent movement through time, as it begins and ends in different moments. With regards to the latter, the action of arriving is instantaneous; it begins and culminates in the same moment.

Alternatively, grammatical aspect uses morphological inflections to signal movement through time. In English and in French, there are two grammatical aspects; in Spanish, there are three. This essay will present examples in Spanish because its morphological structure utilizes all three possible sets of morphemes for aspect, in comparison to French and English. In Spanish, the perfective, imperfective, and progressive aspects all receive their own morphological exponents. The perfective refers to an event fixed in time; in other words, its beginning and end ending are easily locatable (Comrie, 1976; in Cadierno, 2000). Imperfective actions, on the other hand, lack a definite beginning or end. States, habitual actions, and descriptions frequently receive imperfective morphemes because they do not describe the beginning or end of such an action (Bardovi-Harlig, 1994; Comajoan, 2005; LópezOrtega, 2000). Lastly, the progressive aspect is used to refer to actions whose beginning is readily identifiable, but whose end has not yet been realized. In comparison, English has inflections for the progressive and perfective, but not the 
imperfective, and French has inflections for the perfective and imperfective, but not the progressive.

The Spanish verb correr (to run) exemplifies the difference between these three aspects through changes to verbal morphology. The first-person singular form of the past perfective (preterit) corrí (I ran) implies a single, completed action in which the subject of the verb ran. This movement through time is dissimilar to the imperfective past form, corria, which most closely translates to $I$ used to run as a descriptor of habitual action. In contrast, the past progressive form, estaba corriendo, implies that the action was in motion when another, unrelated action interrupted its progress. Therefore, there is a clear connection between the morpheme selected and the meaning that a speaker conveys about movement through time, as the first refers to a single, completed action, the second to a habitual action, and the third to a description of one action before another interrupted its progress.

At the initial stages of development, L2 learners do not use verbal inflections to indicate aspect. Instead, they make use of calendric expressions (last week or la semana pasada, in March or en marzo) to indicate the relationship between actions (Bardovi-Harlig, 2000; Klein \& Perdue, 1997). Since each language has a unique and nuanced system for grammatical aspect, and since not all languages have inflections for all aspects, the learner acquires these forms gradually after sufficient exposure to L2 (Andersen, 1991; Bardovi-Harlig, 1992, 2000; Collins, 2002). For example, English, Spanish, and French, the three languages that are have been the primary objects of research on the $\mathrm{AH}$, demonstrate (a) that, in the case of Spanish and French, historically-related and structurally similar languages do not necessarily have the same morphological systems and (b) that each language's system for aspect is complex. Given these difficulties, it is understandable that L2 learners could be challenged by the acquisition of such forms. The AH provides a perspective into how emerging learners connect lexical aspect to grammatical aspect at early stages of the acquisition process.

\subsection{The aspect hypothesis in second language acquisition}

Andersen (1991) was the first to describe the AH in his longitudinal study of four Anglophone children learning Spanish. The AH predicts that at initial stages of acquisition, L2 learners connect four categories of verbs described by Vendler (1967) accomplishments, activities, achievements, and states - to specific grammatical aspects. According to the AH, it is possible to place any verb within one of these four categories. Research on the $\mathrm{AH}$ has applied three semantic features - dynamicity, punctuality, and telicity - to describe these categories and their relationship to grammatical aspect. Figure 1 offers a visual of the connection between grammatical aspect, semantic features of lexical aspect, and the Vendler (1967) categories. 


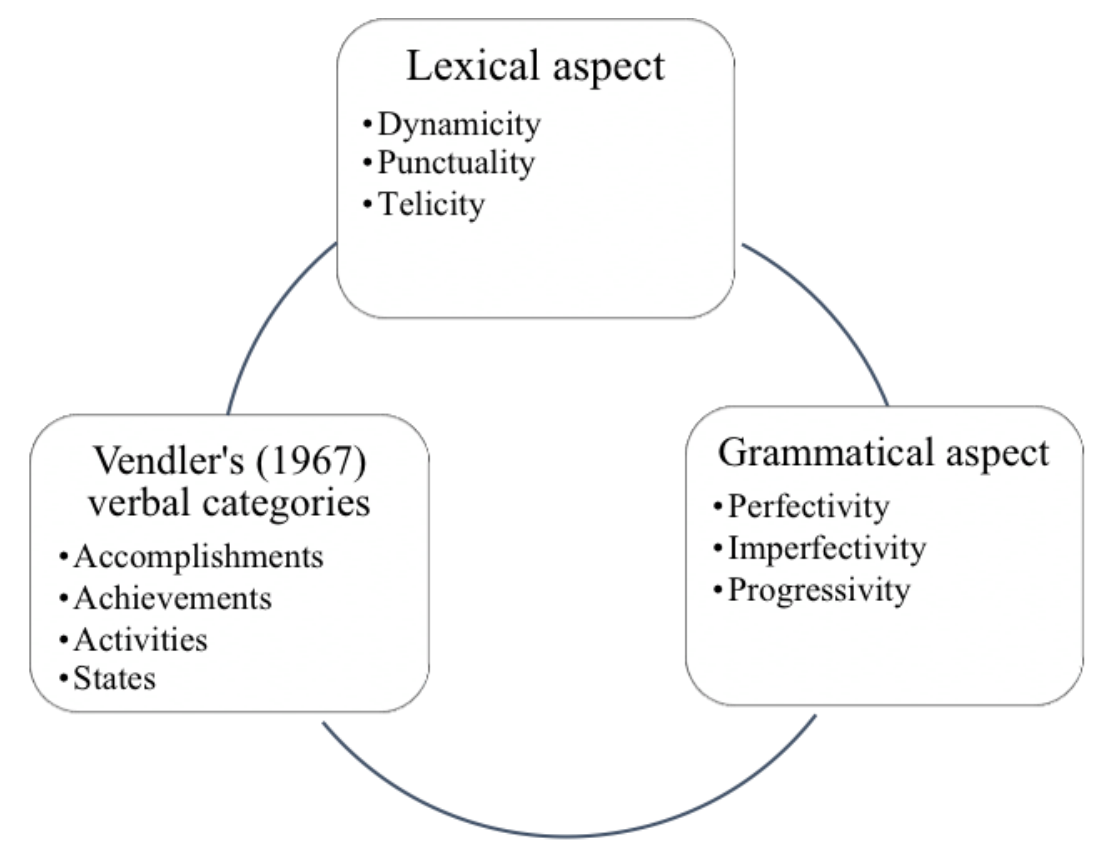

Figure 1. The relationship between grammatical aspect, lexical aspect, and the Vendler (1967) verbal categories as used in Andersen (1991) and subsequent studies on the AH.

Firstly, dynamicity refers to the variability of a verb. An action that is not likely to change over time is [-dynamic]. Such an action cannot be fulfilled as it advances indefinitely through time. In contrast, a [+dynamic] action is one with a changeable nature and that can be completed (Cadierno, 2000). An example of a [+dynamic] verb in Spanish is the verb ganar (to win). This action is only completed, for example, when a team wins a game and the opponent has been defeated. On the other hand, a [-dynamic] verb does not have an implicit endpoint. Ser (to be) is [-dynamic] because it is a state without finality that describes permanent characteristics; there is no clear end to this action.

Secondly, punctuality refers to the duration of an action. A [+punctual] action begins and ends at the same time, while a [-punctual] action begins in one instant and finishes in another. The verb llegar (to arrive) is [+punctual] because the act of arriving is completed as soon as it is initiated. However, the verb jugar (to play) is [punctual] because one can play for a prolonged period of time, and as such this action is not fulfilled instantaneously.

Lastly, telicity refers to the finality of an action. Actions that are [+telic] are those that can be completed within a specific period of time, and those that are [-telic] or atelic are indefinite (Cadierno, 2000; Collins, 2002, 2005). The Spanish verb venir (to come) is [+telic] because it is possible to locate its endpoint: it begins and ends at the same time. However, the action escuchar la música (to listen to music) does not have a natural conclusion, as one cannot "finish" listening to music.

Each of the Vendler (1967) verbal categories are [ \pm dynamic], [ \pm punctual], and [ \pm telic]. Therefore, the inherent lexical aspect described by these three semantic 
features more prototypically associates with a particular grammatical aspect. In other words, language learners rely on the inherent lexical aspect embedded within the verb to determine which grammatical morphemes to apply. According to Andersen (1991), as learners reach higher levels of proficiency, they develop the ability to mark verbs and predicates that do not have prototypical associations between inherent lexical aspect and grammatical aspect. Table 1 displays the proposed sequence of acquisition of markings for specific verbal categories, as well as the semantic features that comprise these categories.

Table 1. The developmental order that Andersen (1991) found regarding the application of temporal inflections to different verb and predicate categories

\begin{tabular}{|c|c|c|c|}
\hline Aspect & Order of verb categories acquired & Prototypes with examples & Development \\
\hline Perfective & $\begin{array}{ll}\text { - } & \text { Accomplishments }[+\mathrm{D},-\mathrm{P},+\mathrm{T}] \\
\text { - } & \text { Achievements }[+\mathrm{D},+\mathrm{P},+\mathrm{T}] \\
\text { - } & \text { Activities }[+\mathrm{D},-\mathrm{P},-\mathrm{T}] \\
\text { - } & \text { States }[-\mathrm{D},-\mathrm{P},-\mathrm{T}]\end{array}$ & $\begin{array}{l}\text { - I won / gané } \\
\text { - I arrived / llegué } \\
\text { - I ran / corrí } \\
\text { - I was / estuve }\end{array}$ & \multirow{3}{*}{ Simultaneous } \\
\hline \multirow[t]{2}{*}{ Progressive } & $\begin{array}{ll}\text { - } & \text { Activities [+D, }-\mathrm{P},-\mathrm{T}] \\
\text { - } & \text { Accomplishments }[+\mathrm{D},-\mathrm{P},+\mathrm{T}] \\
\text { - } & \text { Achievements }[+\mathrm{D},+\mathrm{P},+\mathrm{T}]\end{array}$ & $\begin{array}{l}\text { - I am running / estoy corriendo } \\
\text { - I am winning / estoy ganando } \\
\text { - I am arriving / estoy llegando }\end{array}$ & \\
\hline & \multicolumn{2}{|c|}{ States are seldom used in the progressive. } & \\
\hline Imperfective & $\begin{array}{ll}\text { - } & \text { States }[-\mathrm{D},-\mathrm{P},-\mathrm{T}] \\
\text { - } & \text { Activities }[+\mathrm{D},-\mathrm{P},-\mathrm{T}] \\
\text { - } & \text { Accomplishments }[+\mathrm{D},-\mathrm{P},+\mathrm{T}] \\
\text { - } & \text { Achievements }[+\mathrm{D},+\mathrm{P},+\mathrm{T}]\end{array}$ & $\begin{array}{l}\text { - I was / estaba } \\
\text { - I ran, habitually / corría } \\
\text { - I won, habitually / ganaba } \\
\text { - I arrived, habitually / llegaba }\end{array}$ & $\begin{array}{l}\text { After onset of } \\
\text { other aspects }\end{array}$ \\
\hline
\end{tabular}

In sum, these three semantic features comprise the lexical aspect of a verb. According to early research on the $\mathrm{AH}$, at the beginning of acquisition, L2 learners connect lexical aspect to grammatical aspect based upon these semantic features in the sequence described above. Learners are more likely to use perfective markings on verbs of achievement and accomplishment before they do so with states. Conversely, the AH suggests that learners are more likely to use the imperfective aspect to describe states before accomplishments and achievements, and that the progressive emerges with activity verbs.

As learners develop higher levels of proficiency, the dependence on lexical aspect to determine the grammatical marker for a verb decreases. That is, according to early research, advanced L2 learners develop the ability to apply morphological markers that are not prototypically associated with specific Vendler (1967) categories, such as progressive markings to achievements and perfective markings to activities and states. There exists one exception: Andersen (1991) postulated that states never receive progressive morphology at any stage in acquisition. These observations are consistent with evidence for the $\mathrm{AH}$ based on other studies across a handful of L2s, and with participants with a diversity of L1 backgrounds (Andersen, 1991; Liskin- 
Gasparro, 2000; Salaberry, 2002, 2003 for English-speaking L2 learners; BardoviHarlig, 1992 for L2 French learners of multiple linguistic backgrounds; BardoviHarlig \& Bergström, 1996 for a comparison between the acquisition of L2 English for Francophones and of L2 French for Anglophones; Cadierno, 2000 for L1 Danish learners of L2 Spanish; Collins, 2002, 2005 for L1 English speakers learning L2 French; Izquierdo \& Collins, 2008 for a comparison of Anglophone and Hispanophone learners of L2 French). Although the above citations provide a robust body of evidence that supports the $\mathrm{AH}$, recent studies have problematized the universality of this model.

\section{Methodologies of research review}

The present review of research literature does not present original empirical or qualitative findings; rather, it synthesizes a diversifying body of empirical research across multiple L1 and L2 populations that provides a critical review of the AH. The research presented also encompasses research on naturalistic and instructed learners. Furthermore, the studies cited are both longitudinal and cross-sectional in nature. The broad scope of these studies looks to provide robust evidence for three key caveats of the AH: L1 influence and L1-L2 interface, the role of lexical aspect in the acquisition of temporal morphology, and naturalistic versus instructed L2 learning.

The first claim (regarding L1 influence and L1-L2 interface) explores how certain populations of learners acquire aspect in a way dissimilar to that of others. From the evidence presented below, it would appear that syntactic and semantic similarities between languages have an impact on the development of target-like use of temporal morphemes. In other words, the articles examined cite empirical evidence suggesting that learners whose L1 has a similar set of inflections for aspect as the L2 mark aspect more rapidly and more accurately in the L2 than learners whose L1 does not have such similarity.

Additionally, the role of lexical aspect is of concern to this study. The articles examined provide contrasting evidence to the categorical acquisition of L2 aspectual morphology that Andersen (1991) proposed. Contrary to this study, some longitudinal research has demonstrated that L2 learners' dependence on lexical aspect increases over time, rather than decreases. Furthermore, it appears that early learners may utilize certain semantic features more than others when assigning grammatical morphemes to particular verbs and predicates at early stages of acquisition.

Finally, little research has compared otherwise similar populations of learners that have received L2 instruction with those that have not. Therefore, this article gathers evidence that the role of textbooks and classroom-based instruction has a significant impact on the way in which L2 learners develop accuracy in marking temporality. In fact, when compared with research on naturalistic acquisition, it does not appear that the $\mathrm{AH}$ applies to all learners with the same degree of exactitude. However, this claim lacks the same degree of quantitative evidence as the proceeding two, so future directions for research on this topic are explored. 


\section{Caveats of the AH}

\subsection{L1 influence and L1-L2 interface}

One key area of concern to the AH is crosslinguistic influence and L1-L2 transfer. L1-L2 commonality has been of increasing importance to recent studies because the structural differences between the two languages may have an effect on the degree to which the AH can predict learners' development (Bonilla, 2013; Comajoan, 2005; Comajoan \& Pérez-Saldanya, 2005; Izquierdo \& Collins, 2008; McManus, 2013; Salaberry, 2011).

For example, Izquierdo and Collins (2008) revealed that Spanish-speaking students of L2 French achieved accurate use of perfective and imperfective morphology faster than their English-speaking counterparts in the same study. First, the researchers demonstrated through an analysis of variance (ANOVA) that the Spanish-speaking students displayed greater target-like use of aspectual morphemes than their Englishspeaking counterparts on a cloze test in which participants needed to choose between perfective and imperfective forms. Secondly, these researchers carried out a retrospective analysis with each participant so that they could explain their selection of perfective and imperfective morphemes on the cloze test used to conduct the study.

This offered some evidence for the similarity between French and Spanish, which both have inflections for the imperfective, resulted in a faster development of L2 French aspect inflections for Hispanophone learners than Anglophone learners, who did not have a comparable form in their L1. Therefore, there is an undeniable influence of the L1, particularly when it bears structural similarity to the L2 in question, as was the case for the Spanish-speaking L2 French learners in this study.

Furthermore, Collins (2002) indicated that for her French-speaking L2 English learners, L1 influence affected the production of the past perfective. In French, the linguistic form for the past perfective is identical to that of the present perfective. It is thus not surprising that these learners often produced the present perfective form in English in contexts where the past perfective was warranted, since they are morphologically indistinguishable in their L1.

This evidence that L1 influence affects the selection of L2 aspectual markers points to the possibility the $\mathrm{AH}$ does not apply to all learners equally, since the similarity between the past and present perfective forms in French caused L2 English learners to substitute one for the other. In conjunction with findings that the L1-L2 relationship also influences acquisition, these studies have compiled evidence that not all learners develop aspectual morphology in a congruent way. However, this analysis demonstrates that L1-L2 interface is not the sole factor that questions the generalizability of the $\mathrm{AH}$. 


\subsection{The role of lexical aspect}

Other studies on Anglophones learning L2 Spanish and L2 French have suggested that learners' dependence on lexical aspect increases with proficiency level (LiskinGasparro, 2000; McManus, 2013; Salaberry, 2002, 2011), a claim that is directly contrast to the AH: Andersen (1991) claimed that as proficiency level increased, L2 learners relied less on inherent lexical aspect in the selection of verbal morphemes. Through retrospective analyses similar to those used in Izquierdo and Collins (2008), Liskin-Gasparro (2000) verified that her study's participants - advanced L2 Spanish learners - often relied on lexical aspect to make decisions about which morphemes to use to mark aspect.

Similarly, in her longitudinal study of four adult L2 Spanish learners living in Spain, López-Ortega (2000) demonstrated that, even after prolonged contact with L1 speakers, these participants relied on lexical aspect in the selection of aspectual inflections. This study is particularly interesting because two of the learners had received classroom instruction of Spanish, while two had not. However, the effect of instruction was negligible to the research outcomes. While there were no retrospective analyses in this study to confirm the learners' reliance on lexical aspect, multiple examples demonstrated that both the schooled and unschooled participants predominantly used inflections that were prototypically associated with the Vendler (1967) categories. One example in her data was how learners used the verb ver (to see). This verb is an achievement whose inherent lexical aspect is prototypically associated with the perfective aspect. Therefore, the learners consistently produced the first person singular form of the past perfective, vi, even in contexts where the imperfective form veía was warranted. Salaberry (2011) revealed consistent results in his study of advanced Anglophone L2 Spanish learners, and McManus (2013) reached the same conclusion for advanced L2 French learners.

As a result, there now exist multiple studies that counter Andersen's (1991) claim that learners' dependence on lexical aspect decreases as proficiency level increases, instead suggesting the reverse. These claims do not negate evidence for a developmental sequence of aspectual morphemes; in fact, they support the notion that there exists a predictable way in which L2 learners acquire aspectual morphology. However, these four studies have demonstrated that the $\mathrm{AH}$ accurately predicts development at lower levels of proficiency, but at higher levels, the hypothesis is less precise in predicting learner behavior. If learners continue to rely on lexical aspect at high levels of acquisition, they do not expand their usage of grammatical morphemes to non-prototypical contexts, as is predicted by Andersen (1991).

Additionally, in Haznedar's (2007) longitudinal study of a child with L1 Turkish at initial stages of L2 English acquisition, her subject initially produced past tense markings on [+punctual] achievement verbs and predicates. Conversely, this subject seldom marked [-punctual] verbs and predicates for aspect at this stage, leaving them in infinitive forms without inflection. Subsequently, the learner began marking [+telic] actions with aspect. The findings of this study, if generalizable, suggest that 
punctuality and to a lesser degree telicity are more salient to L2 learners than dynamicity at the earliest stages of acquisition of temporal morphology. This is in contrast to the $\mathrm{AH}$, which suggests that even early-stage learners make use of all three semantic features to determine lexical aspect.

In addition to the influence of the first language and of the similarity between L1 and L2, these recent studies have questioned the predictability of the AH because they reveal an increased or steady dependence on inherent lexical aspect in the selection of verbal morphology. The retrospective analyses in Liskin-Gasparro (2000) indicate that even at advanced levels of acquisition, language learners make use of inherent lexical aspect when determining lexical markings. Moreover, Haznedar (2007) makes the suggestion that certain elements of lexical aspect are more salient to the L2 learner at early stages of acquisition than others. A third and final area of concern to the $\mathrm{AH}$ relates to the nature in which pedagogical materials present grammar, and how such an organization of these materials could impact how learners develop temporal morphology.

\subsection{Naturalistic versus instructed acquisition}

The third and final area in this analysis relates to how different contexts of acquisition affect the way in which L2 learners mark aspect with inflections. Although empirical evidence has not yet directly related textbooks to the way in which L2 learners acquire morphology, the rigid sequence in which these pedagogical materials present new morphological concepts may affect the way in which aspectual morphology develops when compared to natural acquisition. Since the AH proposes an invariable and precise route of acquisition for all learners, findings that instructed L2 learners may follow a different route to the acquisition of aspect weakens the argument that the hypothesis is generalizable to all L2 learners.

Specifically, Comajoan (2005) proposed that L2 textbooks present grammar in a linear sequence. As a result, aspects are presented one by one despite the fact that native speakers use multiple aspects simultaneously in connected discourse. This tendency means that textbooks are built around the structure of a syllabus, presenting grammar components individually instead of simultaneously. For instance, L2 Spanish textbooks frequently present the past perfective (preterit) first, followed by the past imperfective (imperfect) and then the past progressive. Students receive input for perfective morphology long before they receive exposure to any imperfective inflections. The result, according to Comajoan (2005), is that leading up to and while learning the inflections for the past imperfective form, learners default to past perfective morphology. After receiving a sufficient amount of input to both, students begin using lexical aspect to distinguish between grammatical markers, which more closely follows the predictions of the AH.

Therefore, the AH likely cannot explain the acquisition of morphological aspect at the earliest stages of acquisition for classroom-based L2 learners, because these students do not have access to imperfective forms. This has given rise to the Default 
Past Tense Hypothesis (DPTH; Salaberry, 2002), which suggests that at least at the very initial stages of instruction, language learners overgeneralize perfective inflections to all verbs and predicates, regardless of whether these forms convey the desired aspect. The DPTH, however, has not been studied as widely as the AH, and evidence is only sourced from Salaberry's studies (2002, 2003, 2011) on Anglophone L2 Spanish learners. Despite the limited scope of this hypothesis, it aligns with research on input processing and interlanguage. Since students first receive input to past perfective morphology with little to no exposure to imperfective forms, input processing theory (see VanPatten, 1996) suggests these learners will overutilize these forms until they have received enough comprehensible exposure to alternative forms.

In sum, the evidence offered by Comajoan (2005) and Salaberry (2002, 2003, 2011) suggests that classroom learning where L2 textbooks are in circulation may cause learners to overuse particular forms that are presented with greater frequency than and before other inflections. For instance, presenting perfective morphology before imperfective morphology may cause the learner to utilize perfective markings on all verbs, even when the imperfective is warranted, until sufficient exposure to both aspects is achieved.

This claim seems particularly feasible in the light of findings from Dietrich, Klein, and Noyau (1995; as cited in Chan, Finberg, Costello, \& Shirai, 2012), a qualitative, longitudinal analysis of naturalistic L2 learners from diverse linguistic backgrounds. This project observed the use of aspectual morphology among non-instructed L2 learners of English, German, Dutch, French, and Swedish with Punjabi, Italian, Turkish, Arabic, Spanish, and French L1 backgrounds that had contact with the target language throughout the six-year study. Regardless of L1 influence, it appears that these naturalistic learners seldom encoded aspect across the six-year study, but rather relied on pragmatic or lexical resources to express temporality. These findings strengthen the argument that naturalistic learners without formal instruction may not achieve target-like use of aspectual morphology at any stage. It is, however, important to recognize that the findings in this study are qualitative and that in the absence of quantitative data it is difficult to prove that naturalistic learners do not adhere to the findings of the AH. Nonetheless, this study lends support to the claim that naturalistic learners may not attain L2 morphological markers for aspect similarly to the way that instructed L2 learners do, if at all.

These conclusions challenge the AH for multiple reasons. First, early instructed L2 learners receive a high frequency of perfective morphology as input with little to no exposure to imperfective inflections. In accordance with research on input processing theory, such an imbalance in input would affect the way in which early L2 learners mark grammatical aspect. This has given rise to the DPTH, which provides limited quantitative evidence that L2 learners develop temporality in a fashion that does not reflect the predictions of the AH. Finally, Dietrich, Klein, and Noyau (1995) suggest that uninstructed, naturalistic learners do not develop target-like use of aspectual morphemes at any stage of the acquisition process. 
To strengthen these claims, future research on the DPTH should focus on pedagogical materials in other languages in order to provide more robust evidence for the claim that L2 textbooks can affect the developmental trajectory of the learners that use them. Furthermore, longitudinal studies on naturalistic learners must provide empirical evidence in favor of a pattern of acquisition that deviates from the predictions of the $\mathrm{AH}$.

\section{Conclusions}

The AH is based on various studies that have attempted to establish a universal norm for the acquisition of aspect. Although there is extensive evidence supporting this model, the claims examined here problematize the generalization of this hypothesis. L1 influence and L1-L2 commonality have challenged the exactitude of the $\mathrm{AH}$, since it appears that some learners have an easier time adjusting to the temporal system of the L2 if their native language has similar aspectual inflections (Collins, 2002; Izquierdo \& Collins, 2008). Moreover, certain semantic features of lexical aspect - punctuality, followed by telicity - may be more salient to certain learners (Haznedar, 2007).

Furthermore, other studies (Liskin-Gasparro, 2000; López-Ortega, 2000; McManus, 2013; Salaberry, 2011) have shown that dependence on lexical aspect increases with proficiency, instead of decreases, as originally recorded in Andersen (1991). Therefore, the AH remains a credible model at earlier stages of acquisition, but the predicted extension of morphemes to non-prototypical contexts at higher proficiency levels is now questionable in the light of this research. Occasional use of retrospective analyses has corroborated these findings, and future research may wish to incorporate such methodologies in order to more effectively describe learner cognition.

Lastly, Comajoan's (2005) assertions about how pedagogical materials present grammatical aspect have called the accuracy of the $\mathrm{AH}$ at initial stages of acquisition into question. Since early learners are not exposed to multiple aspects, they might initially rely on familiar inflections rather than on lexical factors to distinguish between perfectivity, imperfectivity, and progressivity. Such findings are at the foundation of the DPTH (Salaberry, 2002, 2003, 2011), which, despite limited evidence, aligns with research on input processing (VanPatten, 1996) because learners are more likely to make choices based upon what is familiar to them through more extensive input. The findings in Dietrich, Klein, and Noyau (1995) on naturalistic learners corroborate the claims that naturalistic acquisition differs from instructed acquisition, although additional empirical studies in this area are warranted.

In spite of these claims, the $\mathrm{AH}$ has credibility in at least partially predicting the development of L2 learners' aspectual morphology. Learners continue to use the relationship between lexical aspect and grammatical aspect that Andersen (1991) captured, relating the semantic features of dynamicity, punctuality, and telicity to the four Vendler (1967) verbal categories. 
However, the present review has presented evidence from multiple studies from various languages that suggests that the $\mathrm{AH}$ is prone to $\mathrm{L} 1$ influence, that it is less applicable at higher levels of acquisition, and that it is plausibly not a factor in choosing aspectual morphemes for classroom learners at the earliest stages of acquisition. Future research across a wider span of languages should seek to expand upon the growing number of publications that have investigated the interaction between L1 and L2, the influence of pedagogical materials on the $\mathrm{AH}$, and the possibility that alternative hypotheses such as the DTMH exist to explain acquisition of aspectual morphology in order to strengthen or revise the claims proposed in this analysis.

\section{References}

Andersen, R. (1991). Developmental sequences: The emergence of aspect marking in second language acquisition. In T. Huebner \& C.A. Ferguson (Eds.), Crosscurrents in Second Language Acquisition and Linguistic Theories (305-324). Amsterdam: John Benjamins.

Bardovi-Harlig, K. (1992). The relationship of form and meaning: A cross-sectional study of tense and aspect in the interlanguage of learners of English as a second language. Applied Psycholinguistics, 13, 253-278.

Bardovi-Harlig, K. (1994). Anecdote or evidence? Evaluating support for hypotheses concerning the development of tense and aspect. In E. Tarone, S.M. Gass, \& A.D. Cohen (Eds.), Research Methodology in Second Language Acquisition (41-60). Mahwah, NJ: Lawrence Erlbaum.

Bardovi-Harlig, K. \& Bergström, A. (1996). Acquisition of tense and aspect in second language and foreign language learning: Learner narratives in ESL and FFL. Canadian Modern Language Review, 52, 308-330.

Bardovi-Harlig, K. (2000). Tense and aspect in second language acquisition: Form, meaning, and use. Oxford: Blackwell.

Cadierno, T. (2000). The acquisition of Spanish grammatical aspect by Danish advanced language learners. Spanish Applied Linguistics, 4, 1-53.

Chan, H.L., Finberg, J., Costello, W., \& Shirai, Y. (2012). L2 acquisition of tense-aspect morphology: Lexical aspect, morphological regularity, and transfer. In L. Filipovic \& K.M. Jaszczolt (Eds.), Space and Time in Languages and Cultures: Linguistic Diversity (181-202). Amsterdam: John Benjamins.

Collins, L. (2002). The roles of L1 influence and lexical aspect in the acquisition of temporal morphology. Language Learning, 52(1), 43-94.

Comajoan, L. (2005). The early L2 acquisition of past morphology: Perfective morphology as an aspectual marker or default tense marker? In D. Eddington (Ed.), Selected Proceedings of the 6th Conference on the Acquisition of Spanish and Portuguese as First and Second Languages (31-43). Somerville, MA: Cascadilla Proceedings.

Comrie, B. (1976). Aspect. Cambridge: Cambridge University Press.

Dietrich, R., Klein, W., \& Noyau, C. (1995). The acquisition of temporality in a second language. Amsterdam: John Benjamins.

Haznedar, B. (2007). The acquisition of tense-aspect in child second language English. Second Language Research, 23(4), 383-417. 
Izquierdo, J. \& Collins, L. (2008). The facilitative role of L1 influence in tense-aspect marking: A comparison of Hispanophone and Anglophone learners of French. The Modern Language Journal, 92(3), 350-368.

Klein, W. \& Perdue, C. (1997). The basic variety (or: Couldn't natural languages be much simpler?). Second Language Research, 14, 301-347.

Liskin-Gasparro, J.E. (2000). The use of tense-aspect morphology in Spanish oral narratives: Exploring the perceptions of advanced learners. Hispania, 83(4), 830-844.

McManus, K. (2013). Prototypical influence in second language acquisition: What now for the Aspect Hypothesis. International Review of Applied Linguistics in Language Teaching, 51, 299-322.

Murakami, A. \& Alexopoulou, D. (2016). L1 influence on the acquisition order of English grammatical morphemes. Studies in Second Language Acquisition, 38, 365-401.

Paradis, J., Rice, M.L, Crago, M., \& Marquis, J. (2008). The acquisition of tense in English: Distinguishing child second language development from first language and specific language impairment. Applied Psycholinguistics, 29, 689-722.

Salaberry, R. (2002). Tense and aspect in the selection of Spanish past tense verbal morphology. In R. Salaberry \& Y. Shirai (Eds.), The Acquisition of L2 Tense-Aspect Morphology (397-415). Amsterdam: John Benjamins.

Salaberry, R. (2003). Tense aspect in verbal morphology. Hispania, 86(3), 559-573.

Salaberry, R. (2011). Assessing the effect of lexical aspect and grounding on the acquisition of L2 Spanish past tense morphology among L1 English speakers. Bilingualism: Language and Cognition, 14(2), 184-202.

Shirai, Y. \& Andersen, R.W. (1995). The acquisition of tense-aspect morphology: A prototype account. Language, 71(4), 743-762.

VanPatten, B. (1996). Input processing and grammar instruction: Theory and research. Norwood, NJ: Ablex

Vendler, Z. (1967). Linguistics in philosophy. Ithaca, NY: Cornell University Press.

\section{Copyrights}

Copyright for this article is retained by the author(s), with first publication rights granted to the Journal.

This is an open-access article distributed under the terms and conditions of the Creative Commons Attribution license (CC BY-NC-ND) (http://creativecommons.org/licenses/by-nc-nd/4.0/). 